\title{
EFFECT OF DIFFERENT BLOOD SOURCES ON THE FEEDING TIME OF SAND FLY, PHLEBOTOMUS PAPATASI
}

\author{
By
}

\section{NOURA HEIKAL ROBY ${ }^{1}$, MOHAMED A. HUSSEIN ${ }^{2}$, SAID A. M. DOHA ${ }^{1}$, AND SANAA ABDEL SATTAR ABDEL GHANY'1}

Research and Training Center on Vectors of Diseases ${ }^{1}$, and Department of Entomology ${ }^{2}$, Faculty of Science, Ain Shams University ${ }^{1,2}$, Cairo 11566, Egypt

\section{Abstract}

The feeding time for sand fly females was determined experimentally by feeding of thirty females (3-5 days-old) sand fly Phlebotomus papatasi on different blood sources (human, pigeon, hamster and blab $\mathrm{C}$ mice). Mean feeding time was longest on blab $\mathrm{C}$ mice, 8.55 minutes, followed by hamster, 7.05 minutes, then pigeon, 4.84minutes, and finally human, 4.69 minutes. Significant difference was observed in the feeding time between females fed on hamster and balb c mice but there is no significant difference between females fed on human and pigeon.

Keywords: Egypt, Phlebotomus papatasi, phlebotominae, different blood-source, feeding time.

\section{Introduction}

Sand fly Phlebotomus papatasi (Diptera: Phlebotominae) is vector of leishmaniasis, a disease caused by several species of the genus Leishmania; Kinetoplastida: Trypanosomatidae (Lawyer and Perkins, 2004). The adult male and female sand flies require sugar meal (Killick-Kendrick, 1987; Schlein and Raymond, 1999). Additionally, females need blood meal for the eggs development. Once a suitable host is found, the female sand-fly inserts its mouthparts in a suitable site. The skin is penetrated with active movements of insects for several seconds to minutes may pass until a suitable vessels or hemorrhagic pool is found from where a blood is sucked. This intradermal search for blood is known as probing time (Gillett, 1967; Ribeiro et al, 1985). Species vary in intake of blood meals during a gonotrophic cycle. Some take more than one blood meal on different days, whereas others feed only one time for each batch of eggs (El Kammah, 1972).

In Egypt, endemic foci of zoonotic cutaneous leishmaniasis were reported (Morsy, 1996) and visceral leishmaniasis (Morsy, 1997), and nowadays anthroponotic cutaneous leishmaniasis (Hanafi et al, 2013).

Besides, Phlebotomus papatasii the vector of ZCL are well distributed nearly in all the Egyptian Governorates (Lane, 1986; Morsy et al, 1993; Samy et al, 2014) as well as P. langeroni the vector of IVL in the vicinity of Alexandria (El Sawaf et al, 1984, El Okbi et al, 1989; Kassem et al, 2012) and northern coastal zone to Matrouh Governorate (El-Bahnasawy et al, 2013)

\section{Materials and Methods}

Phlebotomus papatasi were obtained from a laboratory colony originating from sand flies caught in 2013 from El Agamy, Alexandria. Colonies were maintained in an insectary at Research and Training Center on Vectors of Diseases. They were reared at $26 \pm 2{ }^{\circ} \mathrm{C} \& 70-80 \% \mathrm{RH}$ and fed on $30 \%$ sucrose solution. The techniques were adopted (El Kammah, 1972; Modi and Tesh, 1983).

For initial feeding, human volunteer, pigeon, hamster and blab $\mathrm{C}$ mice were placed in a cage with 3-5 days-old female sand fly $P$. papatasi. Both hamster and Balb $\mathrm{C}$ mice were anesthetized with sodium thiopental $(0.5 \mathrm{mg})$, also the abdomen feathers of pigeon were removed to allow direct feeding.

The feeding time taken by the sand flies kept in insectary under controlled temperature and humidity under close observations to determine the beginning of probing and end of feeding. This process was repeated under the same condition with the different sources of blood meal.

Statistical analysis: A univariate analysis of variance (ANOVA) was used to compare the mean number of $P$. papatasi that fed on different blood sources. Duncan's new mul- 
tiple range test (MRT) post hoc analysis was utilized to ascertain the extent of difference between the groups in cases where ANOVA was significant. Probabilities of the F tests were at $\alpha=0.05$ level. All analyses were carried out using IBM SPSS statistics, version 20 for Windows (SPSS Inc., Chicago, IL, USA) and Microsoft ${ }^{\circledR}$ Office Excel 2010.

\section{Results}

The feeding time is defined as the time taken from initial insertion of the mouthparts in the skin until the engorgement. If a female ends a probe unsuccessfully and tries again, the second probing time is measured from the second probing until engorgement.

A probe that ends by removal of the mouthparts without intake of blood is not measured. The time taken by each type of blood sources were arranged as: Blab C mice $>$ Hamster $>$ Pigeon $>$ Human.

Table 1: Means values for feeding time taken per minutes of females $P$. papatasi feed on different blood sources.

\begin{tabular}{|l|c|c|c|}
\hline Groups & $\mathrm{M} \pm \mathrm{SD}$ & Minimum & Maximum \\
\hline Human blood & $4.69 \pm 1.04 \mathrm{a}$ & 3.10 & 6.50 \\
\hline Hamster blood & $7.05 \pm 1.29 \mathrm{~b}$ & 3.11 & 9.10 \\
\hline Blab C mice blood & $8.55 \pm 1.25 \mathrm{c}$ & 6.02 & 11.59 \\
\hline Pigeon blood & $4.84 \pm 1.21 \mathrm{a}$ & 3.15 & 8.32 \\
\hline \multicolumn{3}{|c|}{ Non-significantly $=\mathrm{P}<0.05}$.
\end{tabular}

Mean feeding time was longest on blab $\mathrm{C}$ mice, 8.55 minutes, followed by hamster, 7.05 minutes, then pigeon, 4.84 minutes, and finally human, 4.69 minutes. Statistical analysis showed that there was no significant difference for time taken between fe- males fed on human blood and females fed on pigeon blood. But there was significant difference between females fed on hamster blood and other three groups, also between females fed on blab $\mathrm{C}$ mice blood and other three groups $(\mathrm{P}<0.05)$.

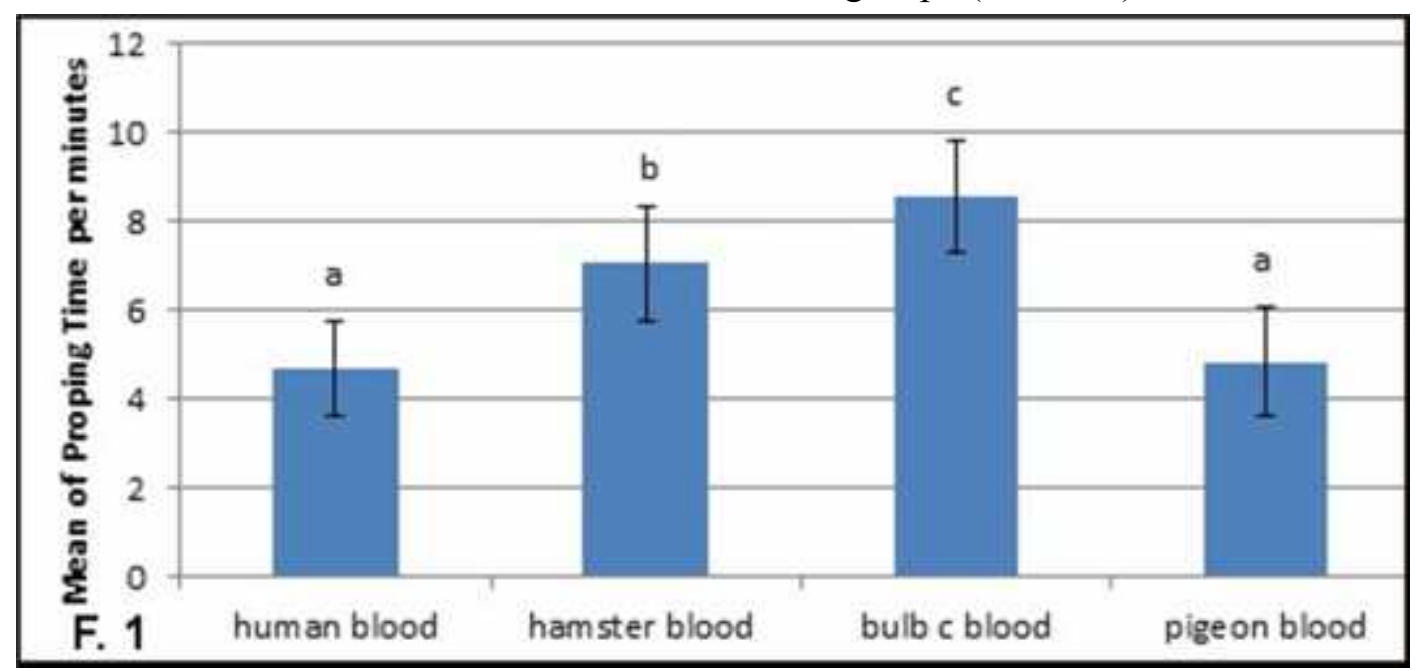

Fig.1: Effect of different blood sources on feeding time as Mean values $( \pm \mathrm{SD})$ of female $P$. papatasi

\section{Discussion}

Among factors that may affect the vectorial capacity to a parasite Leishmania is the probing and feeding periods of the vector. Few previous studies were recorded on feeding time of sand flies that fed on different blood sources. Most of the studies were conducted with either mosquitoes or ticks. Sand flies inject saliva into the mammalian host when probing for a blood meal (Titus and Ribeiro, 1990). In the present study, the feeding time of $P$. papatasi on different blood sources was recorded individually. The mean feeding time was longest on blab $\mathrm{C}$ mice, 8.55 minutes, followed by hamster, 7.05 minutes, then pigeon, 4.84 minutes, and finally human, 4.69 minutes.

The feeding in groups is known to affect the time taken to initiate a blood meal and its duration, but individual feeding was undergone to permit time recording (Tripet et al, 2009). 
The time of feeding needed by tested sand fly females was long as compared to other Diptera. Sand flies seemed to need considerable longer period for either probing or engorgement than mosquitoes. Anopheles aquasalis exhibited the shorter total feeding time of 2.21 minutes than An. homunculus which exhibited 3.28 minutes (Chadee and Beier, 1995). On the other hand, El-Bahnasawy et al. (2014) reported that the human bedbug Cimex lectularis took more or less about 30 minutes as feeding time.

The difference in time of feeding might be attributed to difference in structure of stylets and/or saliva quantity or even vector behavior that assess in the blood feeding time (Mellink et al, 1982; Rossignol et al, 1984) or the feeding behavior (Turell et al, 1996; Reinhardt et al, 2010).

The present results showed that the feeding behavior of $P$. papatasi significantly differed when they were fed on different sources of blood, which directly affected the feeding time. Females fed on hamster or blab $\mathrm{C}$ mice took more time than those fed on human or pigeon. The longer time might be due to the sand fly adaptive to avoid predation by the host (Gillett, 1967) or may be due to the thickness of the host skin. While the skin of human and pigeon permit easier and faster feeding due to the less density of the hair that covers the skin. Also, sand flies may be like other blood-sucking insects such as mosquitoes that have a significant role of saliva that fed on mammalian hosts hence saliva of female insect control the quantity of blood that suck it and also the taken to engorgement (Ribeiro, 2000). Breijo et al. (2014) studied the infestation burden of Haematobia irritans (Linnaeus) (Diptera: Muscidae) among bovines within the same herd and found differences which they attributed to the epidermal thickness of the cattle and the blood intake capacity of the fly. They concluded that the accessibility of blood was a factor that partially explains cattle attractiveness to flies.

Moreover, Baum et al. (2015) in Brazil re- ported that the identification of the blood meal sources of the sand flies using the molecular method was directly linked to the level of digestion of the blood (time-course) and not to the amount of blood that had been ingested or to the presence of inhibitors in the blood.

\section{Conclusion}

Generally speaking, zoonotic cutaneous leishmanias is not only endemic in Egypt, but also in nearly all the Eastern Mediterranean countries. The feeding behavior of sand flies provides valuable epidemiological information about the sand-fly/host interactions. No doubt, studying the feeding time and its relation to the skin of the host has its input in the feasible control measurements of the sandflies.

\section{References}

Baum, M, de Castro, EA, Pinto, MC, Goulart, TM, Baura, W, et al, 2015: Molecular detection of the blood meal source of sand flies (Diptera: Psychodidae) in a transmission area of American cutaneous leishmaniasis, Paraná State, Brazil. Acta Trop. 143:8-12.

Breijo, M, Rocha, S, Ures, X, Pedrana, G, Alonzo, P, et al, 2014: Accessibility of blood affects the attractiveness of cattle to horn flies. Med. Vet. Entomol. 28, 1:116-8.

Chadee, DD, Beier, JC, 1995: Blood-engorgement kinetics of four anopheline mosquitoes from Trinidad, West Indies. Ann. Trop. Med. Parasitol. 89, 1:55-62.

El Bahnasawy, MM, Ahmed, GM, Gaber, W A, Morsy, TA, 2013: The infantile visceral leishmaniasis: could it attack Egyptian north coastal region again? J. Egypt. Soc. Parasitol. 43, 3: 601-8.

El Bahnasawy, MM, Abdel Fadil, EE, Morsy, TA, 2014: Bedbug: is it a missed vector of medical importance or just an annoying and irritating insect? Egyptian Military Medical Journal (EMMJ), 69, 1:74-81.

El Kammah, KM, 1972: Frequency of autogeny in wild-caught Egyptian Phlebotom us papatasi (Scopoli) (Diptera: Psychodidae). J. Med. Entomol. 9:294-8.

El Okbi, LM, Morsy, TA, Khalid, MLM, Salama, MMI, Bebars, M.A, et al, 1989: Some aspects of sandflies of the genus Phlebotomus in 
El Agamy, Alexandria, Egypt. J. Egypt. Soc. Parasitol. 19, 2: 437-46.

EI Sawaf, BM, Beier, JC, Hussein, SM, Kassem, HA, Sattar, SA, 1984: Phlebotomus langeroni: a potential vector of Kala-Azar in the Arab Republic of Egypt. Trans. R. Soc. Trop. Med. Hyg. 78:421-9.

Gillett, JD, 1967: Natural selection and feeding speed in a blood-sucking insect. Proc. R. Soc. Lond. B. Biol. Sci. 167, 1008:316-29.

Hanafi, HA, El-Din el-SM, El-Hossary, SS, Kaldas, RM, Villinski, JT, et al, 2013: Experimental acquisition, development, and transmission of Lei-shmania tropica by Phlebotomus duboscqi. Acta Trop. 125, 1:37-42

Kassem, HA, El Nogoumy, NN, El Sawaf, BM, 2012: Impact of urbanization on the sand fly Phle-botomus langeroni nitzulescu in an old focus of visceral leishmaniasis in Egypt. J. Egypt. Soc. Parasitol. 42, 3:619-24.

Killick-Kendrick, R, 1987: Methods for the study of phlebotomine sandflies: Appendix II, In: The Leishmaniases, Vol. 1; Academic Press London.

Lane, RP, 1986: The sand flies of Egypt (Diptera: Phlebotominae). Bull. Brit. Mus. Nat. Hist. (Entomol.) 52:1-35.

Lawyer, PG, Perkins, PV, 2004: Leishmaniosis and trypanosomiasis. In: Medical Entomology, Revised by B.F. Eldridge and J.D. Edman (eds.), Kluver Academic Publishers, Great Britain.

Mellink, JJ, Poppe, DMC, van Duin, GJT, 1982: Factors affecting the blood-feeding process of a laboratory strain of Aedes aegypti on rodents. Entomol. Exp. Appl. 313:229-38

Modi, GB, Tesh, RB, 1983: A simple technique for mass rearing Lutzomyia longipalpis and Phlebotomus papatasi (Diptera: Psychodidae) in the laboratory. J. Med. Entomol. 20: 568-9.

Morsy, TA, 1996: Cutaneous leishmaniasis in Egypt: Review and comment. J. Egypt. Soc. Parasitol. 26, 1:105-30.

Morsy, TA, 1997: Visceral leishmaniasis with special reference to Egypt (Review and Comment). J. Egypt. Soc. Parasitol. 27, 2:373-96.
Morsy, TA, Aboul Ela, RG, Sarwat, MA, Arafa, MA, el Gozamy, BM, 1993: Some aspects of Phlebotomus papatasi (Scopoli) in greater Cairo, Egypt. J. Egypt. Soc. Parasitol. 2:399416.

Reinhardt, K, Isaac, D, Naylor, R, 2010: Estimating the feeding rate of the bedbug Cimex lectularius in an infested room: an inexpensive method and a case study. Med. Vet. Entomol. $24,1: 46-54$.

Ribeiro, JM, 2000: Blood-feeding in mosquitoes: probing time and salivary gland antihaemostatic activities in representatives of three genera (Aedes, Anopheles, Culex). Med. Vet. Entomol. 14, 2:142-8.

Ribeiro, JM, Sarkis, JJ, Rossignol, PA, Spielman, A, 1985: Aedes aegypti: model for blood finding strategy and prediction of parasite manipulation. Exp. Parasitol. 60, 1:118-32.

Rossignol, PA, Ribeiro, JM, Spielman, A, 1984: Increased intradermal probing time in sporozoite-infected mosquitoes. Am. J. Trop. Med. Hyg. 33, 1:17-20.

Samy, AM, Doha, SA, Kenawy, MA, 2014: Ecology of cutaneous leishmaniasis in Sinai: linking parasites, vectors and hosts. Mem. Inst. Oswaldo Cruz 109, 3:299-306

Schlein, Y, Raymond, LJ, 1999: Sugar meals and longevity of the sandfly Phlebotomus papatasi in an arid focus of Leishmania major in the Jordan Valley. Med. Vet. Entomol. 13, 1: 65-71.

Titus, RG, Ribeiro, JM, 1990: The role of vector saliva in transmission of arthropod-borne disease. Parasitol. Today 6, 5:157-60.

Tripet, F, Cleg, S, EInaiem, DE, Ward, RD, 2009: Cooperative blood feeding and the function and implications of feeding aggregations in the sand fly, Lutzomyia longipalpis (Diptera: Psychodidae). PLoS Negl. Trop. Dis. 3, 8:1-7.

Turell, MJ, Presley, SM, Gad, AM, Cope, SE, Dohm, DJ, et al, 1996: Vector competence of Egyptian mosquitoes for Rift Valley fever virus. Am. J. Trop. Med. Hyg. 54, 2:136-9. 